\title{
Correlation of physical activity and fitness with arches of the foot in children
}

\section{Aleksandra Truszczyńska-Baszak ${ }^{1}$, Justyna Drzał-Grabiec ${ }^{2}$, Maciej Rachwał르. Dorota Chałubińska ${ }^{1}$, Edyta Janowska²}

${ }^{1}$ Faculty of Rehabilitation, Józef Piłsudski University of Physical Education, Warsaw, Poland; ${ }^{2}$ Institute of Physiotherapy, University of Rzeszów, Poland

\section{Summary}

Study aim: Physical activity is crucial for a child's development, as well as for the development of the foot. The aim of this study was to assess the correlation of the level of physical activity and physical fitness with the arches of the foot in children in non-weight-bearing and weight-bearing conditions.

Material and methods: The study population consisted of 92 children aged 10 to 14 years. We assessed their physical fitness with a modified Zuchora test. The modification consisted in choosing three (speed, jumping ability, and flexibility) out of a total of six trials. To assess the physical activity, we used a screening test - the anonymous Moderate to Vigorous Physical Activity questionnaire. To analyze the arches of the foot, we used computer equipment based on the Moiré projection method.

Results: Pearson's chi-squared test did not reveal any significant correlation between physical activity, physical fitness, and longitudinal and transversal arches in children. The percentage of normal and high foot arches increased with increasing levels of physical activity and physical fitness. A Wilcoxon signed-rank test analysis confirmed a statistically significant difference (with $\mathrm{p}<0.001)$ in the longitudinal and transversal arches in measurements in non-weight-bearing and weight-bearing conditions.

Conclusions: 1 . In the examined group, there were functional lateral and longitudinal flat feet. 2. A lowered longitudinal arch foot might reduce physical activity and fitness in adolescents.

Key words: Physical activity - Physical fitness - Arches of the foot - Foot arch measurement

\section{Introduction}

A suitable amount of physical activity is crucial for child development. Physical activity (PA) leads to physical fitness (PF). Limited PA may lead to illnesses, metabolic disorders, and musculoskeletal disorders, such as incorrect foot arches.

The foot is the fundament of the body posture, in both its static and dynamic functions, regardless of the different measures of foot structure [10]. Proper stabilization of the foot on the ground, along with its proper arches, guarantees correct gait [18]. The structure of the foot is formed by a system of longitudinal and transversal arches. The arches regulate the pressure on the soles of the feet in weight-bearing conditions $[6,18]$.

Individual differences in foot structure depend on anthropometric parameters, genetic factors, and lifestyle. Its structure is maintained by muscles, joint capsules, and ligaments [7]. There is a strong relationship between the strength and endurance of lower extremity muscles and the structure of the arches of the foot [2].

Disorders of the arches of the foot have been extensively discussed in the literature. Clarke's angle forms between the C-S line, binding the most internal point of the forefoot with the most internal point of the hindfoot, and the Q-q line, which is the medial tangent of the foot. A range below 28 degrees denotes a flat foot; 28-40 degrees, a lowered foot arch; 40-51 degrees, a normal foot arch; and over 51 degrees, a high foot arch. The transversal arch is assessed according to the Wejsflog index. The Wejsflog index defines the proportions of the foot, i.e. foot length to foot width ratio [9].

Physical activity (PA) is body movement caused by muscle work that leads to energy expenditure higher than the basal metabolic rate $[19,20]$. PA is efficient only when it is done with optimal frequency and intensity. The World Health Organization (WHO) has established norms for PA 


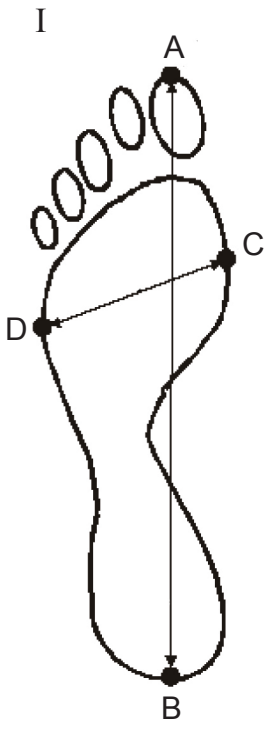

II

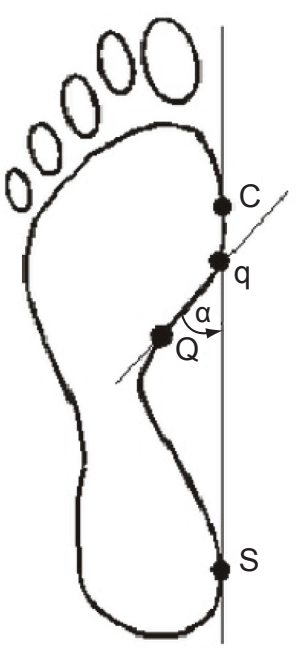

Fig. 1. Calculating the pantographic indexes: I- the Wejsflog index; II - Clarke's angle [9]

for individual age groups. For children and teenagers aged $5-17$, the recommended amount of PA is 60 minutes every day [29]. The benefits of regular PA in children are body mass control, desired bone development and bone mineralization, and an increase in muscle flexibility and endurance $[12,14,16,18]$. Physical activity results in physical fitness [15]. Physical fitness (PF) means that a person is ready for physical tasks that require muscle strength, quickness of movement, and physical efficiency, as well as general health. In children, they are dependent on many factors, such as age, sex, and body build, as well as past injuries, which have a negative effect on PF [24]. The process of progressive development of the foot arch ends mostly between 10 and 13 years of age, and is characterized by specificity in comparison to the overall somatic development. Therefore, the authors selected children aged $10-14$ as a target group [13].

The aim of our study was to assess changes in transversal and longitudinal arches of the foot in children in relation to the PA and PF and in relation to weight-bearing conditions.

\section{Material and methods}

Following the consent of the Bioethical Commission of University of Rzeszów, we qualified 92 children for the study. The children were 10 to 14 years old. The subjects were classified into the respective age groups based on the following principle: e.g. children whose calendar age at the time of testing was between 9.5 and 10.5 years were classified as belonging to the 10 -year-old age subgroup. There were 57 girls (62\%) and 35 boys (38\%) in the group. Ten-year-old children constituted $10.9 \%$ of the study population (10 subjects); 11-year-olds, $25 \%$ (23 subjects); 12-year-olds, 35.9\% (33 subjects), 13-yearolds, $20.7 \%$; 14-year-olds, $7.6 \%$ (7 subjects). The children were students in primary school in year 4,5 , or 6 , in the region of Podkarpacie. Their mean body height was $153.2 \pm 10.5 \mathrm{~cm}$, and mean body mass was $46.3 \pm 13.0 \mathrm{~kg}$. Based on a growth chart the BMI was calculated; mean BMI was $19.4 \pm 3.6\left(\mathrm{~kg} / \mathrm{m}^{2}\right)$. Most of the children (68-73.9\%) had weight normal BMI, 8 were below the norm, and 8 were overweight or obese.

Criteria for students' inclusion in the study were: age 10 to 14 years, consent to participate in the study, no pain of the locomotor system reported, no injury within 6 months prior to the study.

Criteria for students' exclusion were: neurological and orthopaedic disorders of the locomotor system, internal diseases.

The study was conducted in two primary schools. Fitness tests were conducted in a gym in the presence of a teacher. The physical activity questionnaires were filled out in the classroom. Computer foot measurements were conducted in the office of the school nurse. All conditions in which the study was conducted were the same for all of our subjects.

\section{Physical fitness assessment method}

We assessed children's physical fitness (PF) with a modified Zuchora test. Following a warm-up and test demonstration, we asked the children to complete three out of a total of six trials: speed, jumping ability, and flexibility trials [29]. All trial results were registered with the same measuring equipment. We cheered on the children, so that they did their best in the trials. The children did teach trial twice. We calculated an average of two results and then scored them according to an official scoreboard. Then, we calculated the trial results according to the age and sex of each child [3].

The speed trial consisted of fast stationary running and clapping hands under a bent knee for 10 seconds. We counted the number of claps. The jumping ability trial was a standing long jump. The subjects measured the jumping distance with their own feet (the result was rounded up in case of length greater than half a foot, and down if it was less than half a foot). The flexibility trial consisted of standing upright and then slowly and constantly bending the trunk forward. Bending the knees meant failing the trial. Table 1 shows assessment norms for summed up results of all the three trials. All tests were performed on the same day by an experienced physical education teacher and a qualified physiotherapist.

\section{Physical activity assessment method}

To assess the physical activity of the children, we used a screening test devised by Prochaska et al. - the anonymous Moderate to Vigorous Physical Activity (MVPA) questionnaire [22]. To calculate the MVPA index, we asked the subjects the following questions: 
Table 1. Assessment norms for physical fitness for children aged 10 to 14 years, according to Bartkiewicz [3]

\begin{tabular}{lcccccc}
\hline \multirow{2}{*}{ Age } & \multicolumn{7}{c}{ Fitness assessment in points } \\
\cline { 2 - 7 } & Minimum & Satisfactory & Good & Very good & Superior & Prominent \\
\hline $9-10$ & 3 & 5.5 & 7.5 & 8.5 & 11.5 & 13.5 \\
$11-12$ & 3 & 5.5 & 8 & 10 & 12.5 & 14.5 \\
$13-15$ & 3 & 6 & 8.5 & 11 & 13.5 & 15.5 \\
\hline
\end{tabular}

1. Out of the last 7 days, on how many days did you spend at least 60 minutes doing physical activity?

2. In a typical week, on how many days do you spend at least 60 minutes doing physical activity (including Physical Education lessons)?

When completing the test a physiotherapist explained all concerns. The possible answer range was 0 to 7 days. On this basis, we calculated the average number of days in which the children spent at least 60 minutes on physical activity. According to scientists and WHO experts, children should be physically active a minimum of five times a week for a minimum of 60 minutes each time. Therefore, MVPA $=5.5$ days per week [28].

The following classification is used in the literature:

1. Physically inactive child $=0-1$ day per week;

2. Low physical activity $=2-3$ days per week;

3. Moderately physically active child $=3.5-5$ days per week;

4. Physically active child $=5.5-7$ days per week.

We surveyed sedentary behaviour of the children with questions concerning the time spent using computers, smartphones, and watching TV. The answers allowed us to calculate the total time of these activities throughout the week. Excessive screen time is linked to negative consequences, and the American Academy of Pediatrics (AAP) recommends that the total screen time not exceed 2 hours a day, or 14 hours a week [1]. The following classification is used in the literature: screen time shorter than $7 \mathrm{~h}$ a week is very limited sedentarism; screen time between 7 and 14 hours a week is limited sedentarism; 14 to 28 hours a week is moderate sedentarism; more than 28 hours a week is excessive sedentarism.

\section{Foot arch assessment methods}

To assess arches of the foot, the plantography examination was used. Computer equipment devised for foot analysis - a podoscope with a 3D scanner - was produced by CQ Elektronik System. The tool provides developed and refined podoscope assessment. Apart from the image (plantoconturogram), the equipment provides information on the spatial structure of the foot. The results obtained are repeatable and comparable [9]. The reference values of the assessed parameters, i.e. Clarke's angle and Wejsflog index, are presented above.

\section{Statistical analysis}

We checked whether the distribution of the Wejsflog index and Clarke's angle (CL) was normal with the ShapiroWilk test. To check correlations between the qualitative variables measured, we used Pearson's chi-squared test of independence. To compare foot parameters in weightbearing and in non-weight-bearing conditions (sitting position), we used the Wilcoxon signed-rank test. We set the test significance at $p<0.05$. To analyze the results, we used the statistical software suite STATISTICA for Windows 10.0.

\section{Results}

There was no evidence of a statistically significant relationship between the occurrence of foot defects on the basis of the Wejsflog index (Table 2) and of the Clark index (Table 3), and BMI of the children.

Results of the Zuchora physical fitness test are presented in Figure 2.

Table. 2. Characteristics of the group based on the Wejsflog index and BMI

\begin{tabular}{|c|c|c|c|c|c|c|c|c|c|c|}
\hline & \multirow{2}{*}{ Arch type } & \multicolumn{2}{|c|}{ Whole group } & \multicolumn{2}{|c|}{ Underweight } & \multicolumn{2}{|c|}{ Norm } & \multicolumn{2}{|c|}{ Overweight } & \multirow{2}{*}{$\mathrm{p}$} \\
\hline & & $\mathrm{N}$ & $\%$ & $\mathrm{~N}$ & $\%$ & $\mathrm{~N}$ & $\%$ & $\mathrm{~N}$ & $\%$ & \\
\hline \multirow{2}{*}{ Right foot } & Transverse flat feet & 12 & 13.0 & 0 & 0.0 & 8 & 11.8 & 4 & 25.0 & \multirow{2}{*}{0.1906} \\
\hline & Correct transverse arch & 80 & 87.0 & 8 & 100 & 60 & 88.2 & 12 & 75.0 & \\
\hline \multirow{2}{*}{ Left foot } & Transverse flat feet & 16 & 17.4 & 0 & 0 & 11 & 16.2 & 5 & 31.3 & \multirow{2}{*}{0.1428} \\
\hline & Correct transverse arch & 76 & 82.6 & 8 & 100 & 57 & 83.8 & 11 & 68.8 & \\
\hline
\end{tabular}


Table 3. Characteristics of the group based on the Clarke index and BMI

\begin{tabular}{|c|c|c|c|c|c|c|c|c|c|c|}
\hline & \multirow{2}{*}{ Arch type } & \multicolumn{2}{|c|}{ Whole group } & \multicolumn{2}{|c|}{ Underweight } & \multicolumn{2}{|c|}{ Norm } & \multicolumn{2}{|c|}{ Overweight } & \multirow{2}{*}{$\mathrm{p}$} \\
\hline & & $\mathrm{N}$ & $\%$ & $\mathrm{~N}$ & $\%$ & $\mathrm{~N}$ & $\%$ & $\mathrm{~N}$ & $\%$ & \\
\hline \multirow{4}{*}{ Right foot } & Flat foot & 9 & 9.8 & 0 & 0.0 & 7 & 10.3 & 2 & 12.5 & \multirow{4}{*}{0.4814} \\
\hline & Lowered transverse arch & 19 & 20.7 & 0 & 0.0 & 16 & 23.5 & 3 & 18.8 & \\
\hline & Correct transverse arch & 37 & 40.2 & 5 & 62.5 & 24 & 35.3 & 8 & 50.0 & \\
\hline & Increased transverse arch & 27 & 29.3 & 3 & 37.5 & 21 & 30.9 & 3 & 18.8 & \\
\hline \multirow{4}{*}{ Left foot } & Flat foot & 6 & 6.5 & 0 & 0.0 & 4 & 5.9 & 2 & 12.5 & \multirow{4}{*}{0.7655} \\
\hline & Lowered transverse arch & 22 & 23.9 & 1 & 12.5 & 16 & 23.5 & 5 & 31.3 & \\
\hline & Correct transverse arch & 42 & 45.7 & 4 & 50.0 & 32 & 47.1 & 6 & 37.5 & \\
\hline & Increased transverse arch & 22 & 23.9 & 3 & 37.5 & 16 & 23.5 & 3 & 18.8 & \\
\hline
\end{tabular}

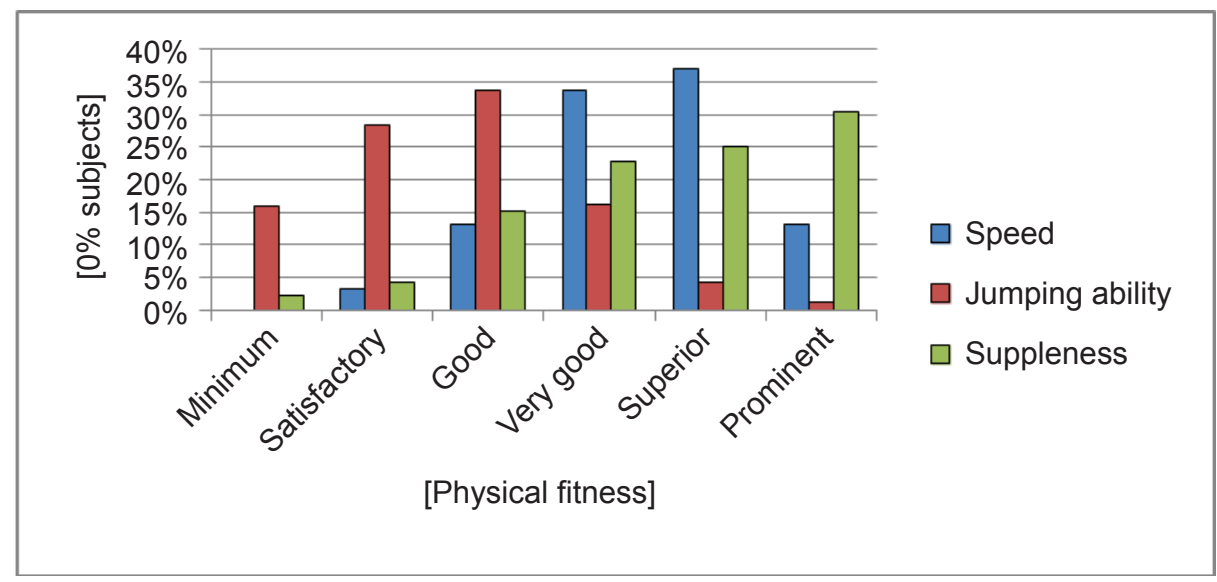

Fig. 2. Physical fitness assessment for children aged 10 to 14 years - tests of speed, jumping ability, and supplenessflexibility, according to Zuchora

These results were then transformed according to the criteria for the Zuchora test. The mean result scored by the children was 11.6 out of 18 points. The lowest result scored was 6 points, and the highest result was 17 points. Most children had very good or superior physical fitness (36 and 25 children, respectively).

As far as the physical activity assessment was concerned, the children scored MVPA points as follows: the mean result was $4.6 \pm 1.3$ points. Then, the results of individual children were transformed according to the criteria for the physical activity test MVPA. The children's activity was assessed in three bands. Figure 3 presents the assessments.

As in the tests above, we transformed the children's activity level results according to relevant criteria. We then assessed their sedentary levels in four bands (Table 4).

\section{Assessment of the longitudinal and transversal foot arches in non-weight-bearing and weight-bearing conditions}

We conducted foot measurements in non-weight-bearing and weight-bearing conditions. The measurements of the Wejsflog index showed that transversely flat feet were more commonly revealed in weight-bearing conditions $(\mathrm{n}=14,15.2 \%)$ than in non-weight-bearing conditions $(\mathrm{n}=4,4.4 \%)$. Transversely flat feet means the situation when the ratio between foot length and width is between 2.00 and 2.50 [9]. Clarke's angle measurements of longitudinal arches in non-weight-bearing conditions revealed that high foot arches were the most common $(\mathrm{n}=53$, $57.6 \%)$, followed by normal foot arches $(\mathrm{n}=30,32.9 \%)$,

Table 4. Graphic and numeric interpretation of sedentary levels - interpretation of results

\begin{tabular}{lcc}
\hline Sedentary level - result interpretation & $\mathrm{N}$ & $\%$ \\
\hline Very limited sedentarism & 15 & $16.3 \%$ \\
Limited sedentarism & 33 & $35.9 \%$ \\
Moderate sedentarism & 39 & $42.4 \%$ \\
Excessive sedentarism & 5 & $5.4 \%$ \\
Total & 92 & $100.0 \%$ \\
\hline
\end{tabular}




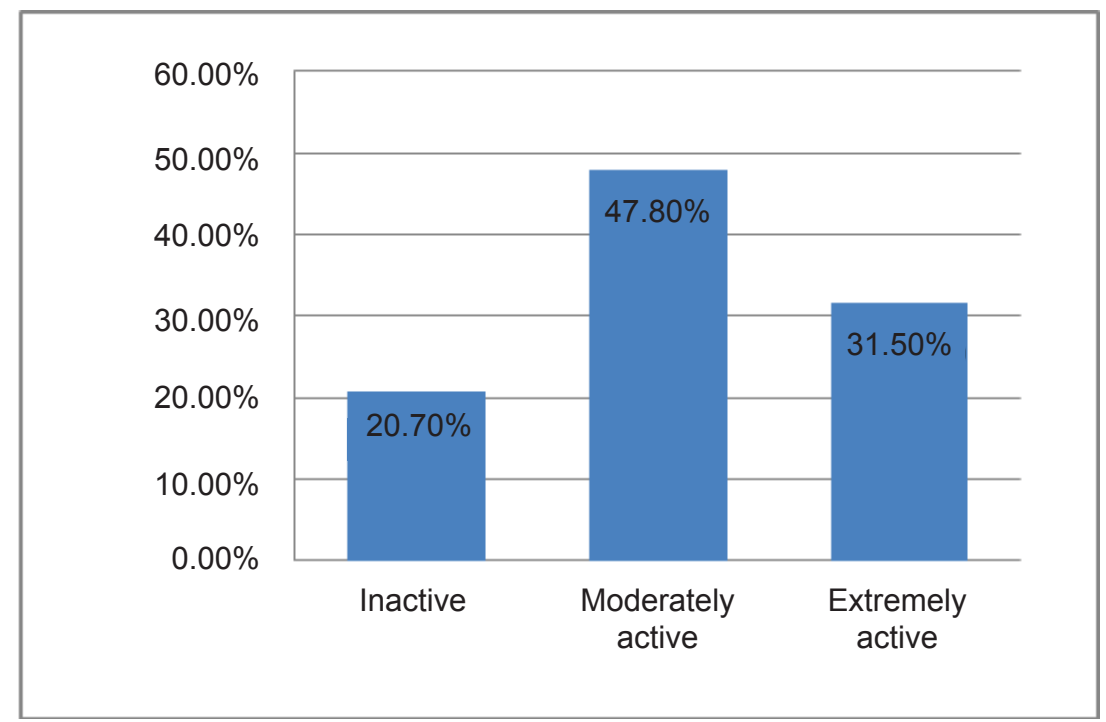

Fig. 3. A graphic interpretation of physical activity levels on the basis of MVPA

and then by lowered foot arches and flat feet $(n=9,9.5 \%)$. In weight-bearing conditions, the most common type of longitudinal arches was normal arches $(n=39,43.9 \%)$. Twenty-five children (26.6\%) had high longitudinal arches, 20 children $(22.3 \%)$ had lowered arches, and $8(8.2 \%)$ had flat feet. The comparison of foot parameters in weightbearing and non-weight-bearing conditions confirmed highly significant differences at $\mathrm{p}<0.001 * * *$ for parameters of longitudinal and transversal foot arches. Table 5 presents the detailed data.

\section{Physical fitness and arches of the foot}

Pearson's chi-squared test analysis did not reveal any statistically significant correlations $(\mathrm{p}<0.05)$ between foot arch disorders based on either the Wejsflog index
( $P=0.8495$ for the right foot, $\mathrm{P}=0.4472$ for the left foot $)$ or Clarke's angle ( $\mathrm{P}=0.628$ for the right foot, $\mathrm{P}=0.1697$ for the left foot) with the level of physical fitness in the study population of children, as assessed with the Zuchora test. It is important to stress, however, that children whose physical fitness was very good or prominent did not have transversely flat feet at all, and that lowered longitudinal arches were four times less common in them than in children whose physical fitness was low.

\section{Physical activity and arches of the foot}

Pearson's chi-squared test analysis did not reveal any statistically significant correlations $(p<0.05)$ between foot arch disorders, as assessed with Clarke's angle measurements, and the children's physical activity, as assessed

Table 5. Foot parameters in measurements in weight-bearing and non-weight-bearing conditions

\begin{tabular}{|c|c|c|c|c|c|c|c|}
\hline \multirow{2}{*}{ Foot parameters } & \multicolumn{3}{|c|}{$\begin{array}{c}\text { Measurement } \\
\text { in non-weight-bearing conditions }\end{array}$} & \multicolumn{3}{|c|}{$\begin{array}{c}\text { Measurement } \\
\text { in weight-bearing conditions }\end{array}$} & \multirow{2}{*}{ Wilcoxon signed-rank test } \\
\hline & $\bar{x}$ & $\mathrm{Me}$ & sd. & $\bar{x}$ & $\mathrm{Me}$ & sd. & \\
\hline Length R & 215.3 & 216.5 & 14.6 & 219.0 & 219.0 & 15.7 & $Z=6.46, p<0.001$ \\
\hline Length $\mathrm{R}$ & 217.1 & 217.5 & 15.3 & 219.2 & 221.5 & 14.2 & $\mathrm{Z}=4.99, \mathrm{p}<0.001$ \\
\hline Length (R-L) & -1.8 & -1.0 & 5.7 & -0.2 & -1.0 & 7.9 & $Z=1.85, p=0.0641$ \\
\hline Width R & 76.9 & 77.0 & 7.2 & 80.1 & 79.5 & 7.0 & $Z=5.80, p<0.001$ \\
\hline Width L & 75.7 & 76.0 & 7.2 & 80.9 & 81.0 & 7.0 & $Z=7.15, p<0.001$ \\
\hline Width (R-L) & 1.2 & 1.0 & 4.5 & -0.7 & -1.0 & 4.7 & $\mathrm{Z}=3.32, \mathrm{p}<0.001$ \\
\hline Length/Width R & 2.8 & 2.8 & 0.2 & 2.7 & 2.7 & 0.2 & $\mathrm{Z}=3.83, \mathrm{p}<0.001$ \\
\hline Length /Width L & 2.9 & 2.9 & 0.2 & 2.7 & 2.7 & 0.2 & $Z=6.79, p<0.001$ \\
\hline Length/Width R-L & -2.6 & -1.9 & 7.0 & 0.6 & 1.1 & 7.2 & $\mathrm{Z}=3.77, \mathrm{p}<0.001$ \\
\hline CL R & 55.3 & 52.7 & 33.9 & 42.9 & 45.0 & 12.2 & $\mathrm{Z}=6.90, \mathrm{p}<0.001$ \\
\hline CL L & 53.7 & 52.7 & 24.8 & 45.4 & 46.0 & 18.4 & $\mathrm{Z}=5.87, \mathrm{p}<0.001$ \\
\hline
\end{tabular}


Table 6. Correlation between body weight, height and BMI in relation to the results of tests of physical fitness and physical activity

\begin{tabular}{lccc}
\hline Variables & R Spearman & $\mathrm{t}(\mathrm{N}-2)$ & $\mathrm{p}$ \\
\hline Body mass [kg] \& Zuchora Test & -0.074 & -0.70 & 0.4858 \\
Body mass [kg] \& MVPA [points] & -0.083 & -0.79 & 0.4288 \\
Body mass [kg] \& sedentarism [points] & 0.123 & 1.17 & 0.2446 \\
Height [cm] \& Zuchora Test [pkt.] & 0.094 & 0.90 & 0.3711 \\
Height [cm] \& MVPA [points] & 0.131 & 1.25 & 0.2131 \\
Height [cm] \& sedentarism [points] & 0.085 & 0.81 & 0.4226 \\
BMI [kg/m2] \& Zuchora Test [points] & -0.234 & -2.29 & $0.0245^{*}$ \\
BMI [kg/m2] \& MVPA [points] & -0.269 & -2.65 & $0.0096^{* *}$ \\
BMI [kg/m2] \& sedentarism [points] & 0.109 & 1.05 & 0.2988 \\
\hline
\end{tabular}

with MVPA. However, lowered foot arches $(\mathrm{n}=15)$ and flat feet $(n=7)$ were found in children whose physical activity was minimum or moderate, and normal feet or high foot arches were more common in physically active children $(\mathrm{n}=25)$.

Correlations between body weight, height and BMI in relation to the results of tests of physical fitness and physical activity are presented in Table 6 .

A significant relationship was found between BMI and physical fitness measured by the Zuchora test $(p=0.0245)$ and also a highly statistically significant relationship $(p=0.0096)$ between the BMI of children and their physical activity. The obtained correlation values $(\mathrm{R})$ for these relationships were, however, weak $(\mathrm{R}=0.3)$ and their orientation was negative.

\section{Discussion}

Sedentary lifestyle might be one of the causes for foot arch disorders [8]. Tong and Kong found a correlation between the type of arches of the foot and injuries to the lower extremities. In the most common foot disorder, i.e. flat feet, there are significant changes to the talocalcanean joint and to the talonavicular joint, which result in an increased risk of injury [25]. It has been proven, too, that flat feet in children are related to an incorrect distribution of static forces that leads to the forefoot being in a lesser pronation in gait than in normal feet [26].

Our study showed that decreased physical activity, sedentary lifestyle, and decreased physical fitness influence the arches of the foot. However, we did not find a significant correlation between the variables. Based on Mueller's studies, which found that static and dynamic measurements of feet change with a child's age, one may presume that a correlation of the above mentioned variables in a wider age group could develop differently [17].
We analyzed the longitudinal arches on the basis of Clarke's angle values; it is a reliable, sensitive, and practical index [21]. Clarke's angle values in non-weight-bearing and weight-bearing conditions revealed statistically significant differences. Therefore, it may prove useful to study the impact of BMI on foot arches in the study population of children.

Rykała et al. studied a group of 182 children aged 7 to 10 years. They used the photogrammetric method. In weight-bearing conditions, they found worse longitudinal arches in boys than in girls, yet the measurement results of both groups were within the normal range [24].

Physical activity is an element of preventive healthcare. It triggers adaptive processes in the body. Our results proved beneficial tendencies in physically active children. Studies by Furgał and Adamczyk on nine - and ten-yearold children seem to confirm our findings. They found that less active children had more foot arch disorders $-62.5 \%$ of girls and $39.5 \%$ of boys who did not perform any physical activity outside their PE lessons had lowered foot arches, as revealed with Clarke's angle and Wejsflog index measurements. Regular physical activity ensured normal foot arches in children [9].

We did not find any statistically significant correlations between foot disorders and the levels of physical fitness in children. We did find, however, that children of superior physical fitness did not have transversely flat feet, and that longitudinally flat feet were most common in children whose physical fitness was lowest.

The foot is one of the links of the human kinematic chain. Twomey and McIntosh conducted a three-dimensional gait analysis of subject with healthy and flat feet. They found increased outer rotation in the hip and a different positioning of the lower limb axis in subjects with flat feet [26]. This shows that a disorder of foot arches negatively affects the functioning of the whole body and the body posture [4]. 
According to the American Orthopaedic Foot and Ankle Society, the issue of flat feet or high foot arches rarely requires specialist treatment [2]. Well-designed footwear and regular physical activity support the correct development of the arches of the foot $[6,11]$.

\section{Limitations of the study}

There were many factors considered in the study. The interactions between variables, and reference values used by different authors make the comparison of results slightly difficult. Therefore, the generalizations and conclusions drawn may not always be unambiguous. Different methodologies of studies quoted, using different measurement methods and borderlines between foot disorders and healthy feet, levels of physical fitness and physical activity, seem to have been additional difficulties.

\section{The value of the study}

Studies in foot structure parameters dependent on physical activity and physical fitness are essential for the physiotherapeutic recommendations for everyday functioning of the patients. An explicit proof that physical activity and physical fitness levels are related to foot structure parameters will allow for the inclusion of specific exercises in the therapy of children with foot disorders. Therefore, the therapy will be more efficient, and the tasks for patients will be more complex.

\section{Conclusions}

1. In the examined group, there were functional lateral and longitudinal flat feet.

2. A lowered longitudinal arch foot might reduce physical activity and fitness in adolescents.

\section{Conflict of interest: Authors state no conflict of interest.}

\section{References}

1. American Academy of Pediatrics, Committee on Public Education. (2001) Children, adolescents, and television. Pediatrics, 107(2): 423-426.

2. American Orthopaedic Foot \& Ankle Society. Footcare a step in the right direction, http://www.aofas.org/footcaremd/overview/Pages/Glossary.aspx dostęp $\mathrm{z}$ dnia 31.01.2017.

3. Bartkiewicz J. (1995) ABC physical fitness. Guidance for girls and boys aged 10-15 years. STENTOR, Warsaw, [in Polish].

4. Branthwaite H., Pandyan A., Chockalingam N. (2012) Function of the triceps surae muscle group in low and high arched feet: an exploratory study. Foot (Edinb.), 22(2): 56-59.

5. Chang H.W., Chieh H.F., Lin C.J., Su F.C., Tsai M.J. (2014) The relationships between foot arch volumes and dynamic plantar pressure during midstance of walking in preschool children. PLoS One 15, 9(4): e94535.

6. Dare D.M., Dodwell E.R. (2014) Pediatric flatfoot: cause, epidemiology, assessment, and treatment. Curr. Opin. Pediatr., 26(1): 93-100.

7. Dzięcioł Z., Kuryliszyn-Moskal A., Dzięcioł J. (2015) Application of plantography examination to the assessment of foot deformity in patients with rheumatoid arthritis. Arch. Med. Sci., 11(5): 1015-1020.

8. Fan J., Brown B.B., Hanson H., Kowaleski-Jones L., Smith K.R., Zick C.D. (2013) Moderate to vigorous physical activity and weight outcomes: does every minute count? Am. J. Health Promot., 28(1): 41-49.

9. Furgał W., Adamczyk A. (2008) Foot arch formation in children, depending on the level of physical activity. Med. Sport., 5(6): 311-317, [in Polish].

10. Hillstrom H.J., Song J., Kraszewski A.P., Hafer J.F., Mootanah R., Dufour A.B., Chow B.S., Deland J.T. (2013) Foot type biomechanics part 1: structure and function of the asymptomatic foot. Gait Posture, 37(3): 445-451.

11. Hogan B. (2014) Choosing the right protective footwear. Occup. Health Saf., 83(9): 83-84.

12. Klentrou P. (2016) Influence of Exercise and Training on Critical Stages of Bone Growth and Development. Pediatr. Exerc. Sci., 28(2): 178-186. DOI: 10.1123/pes.20150265. Epub. 2016 Feb 17.

13. Klimczyk M., Stec M. (2014) The physical and motor development of 9-year-old children attending football classes in "football school for children". Pedagogics, Psychology, Medical-Biological Problems of Physical Training and Sports, 12: 65-69. DOI: 10.15561/18189172.2014.1212.

14. Krul M., van der Wouden J.C., Schellevis F.G., van Suijlekom-Smit L.W.A., Koes B.W. (2009) Musculoskeletal problems in overweight and obese children. Ann. Fam. Med. 7: 352-356.

15. Malina R.M., Katzmarzyk P.T. (2008) Physical activity and fitness in an international growth standard for preadolescent and adolescent children. Food Nutr. Bull., 27(4): 295-313.

16. Manske S.L., Lorincz C.R., Zernicke R.F. (2009) Bone Health: Part 2, Physical Activity. Sports Health 1: 341-346.

17. Müller S., Carlsohn A., Müller J., Baur H., Mayer F. (2012) Static and dynamic foot characteristics in children aged 1-13 years: a cross-sectional study. Gait Posture, 35(3): 389-394.

18. Mussolino M.E., Looker A.C., Orwoll E.S. (2001) Jogging and bone mineral density in men: results from NHANES III. Am. J. Public. Health, 91: 1056-1059. 
19. Must A., Tybor D.J. (2005) Physical activity and sedentary behavior: a review of longitudinal studies of weight and adiposity in youth. Int. J. Obes., (Lond) 29 (Suppl 2): S84-96.

20. Ortega F.B., Ruiz J.R., Castillo M.J., Sjostrom M. (2008) Physical fitness in childhood and adolescence: a powerful marker of health. Int. J. Obes., (Lond) 32(1): 1-11.

21. Pauk J., Ihnatouski M., Najafi B. (2014) Assessing plantar pressure distribution in children with flatfoot arch: application of the Clarke angle. J. Am. Podiatr. Med. Assoc., 104(6): 622-632.

22. Prochaska J.J., Sailis J.F., Long B. (2001) A physical activity screening measure for use with adolescents in primary care. Arch. Pediatr. Adolesc. Med., 155: 554-559.

23. Rexen C.T., Ersbøll A.K., Wedderkopp N., Andersen A.B. (2016) Longitudinal influence of musculo-skeletal injuries and extra physical education on physical fitness in schoolchildren. Scand. J. Med. Sci. Sports, 26(12): 1470-1479. DOI: 10.1111/sms.12618. Epub 2015 Dec 1.

24. Rykała J., Snela S., Drzał-Grabiec J., Podgórska J., Nowicka J., Kosiba W. (2013) Rating longitudinal arch and transverse feet under unloading and loading own weight in children aged 7-10. Prz. Med. Uniw. Rzesz. Inst. Leków, 2: 183-193, [in Polish].
25. Tong J.W., Kong P.W. (2013) Association between foot type and lower extremity injuries: systematic literature review with meta-analysis, J. Orthop. Sports Phys. Ther., 43(10): 700-714.

26. Twomey D., McIntosh A.S., Simon J., Lowe K., Wolf S.I. (2010) Kinematic differences between normal and low arched feet in children using the Heidelberg foot measurement method. Gait Posture, 32(1): 1-5.

26. Twomey D.M., McIntosh A.S. (2012) The effects of low arched feet on lower limb gait kinematics in children. Foot, (Edinb.), 22(2): 60-65.

27. World Health Organization: Obesity preventing and managing the global epidemic (2000) WHO Technical Report Series 894. WHO Geneva.

28. World Health Organization (2010) Global recommendations on physical activity for health 2013; Geneva: 2013.

29. Zuchora K. Index of physical fitness. ZG SZS Warsaw, 1984.

\section{Received 03.10.2016 \\ Accepted 28.02.2017}

(C) University of Physical Education, Warsaw, Poland 